\title{
LA METÁFORA Y LOS ENUNCIADOS METAFÓRICOS: UNA PROPUESTA TEÓRICO- METODOLÓGICA ${ }^{1}$
}

\author{
Beatriz Hall \\ Universidad de Buenos Aires / Universidad Nacional de Lomas de Zamora (Argentina) \\ hallbeatriz@gmail.com
}

Recibido: 15/08/2020 - Aprobado: 28/09/2020 - Publicado: 15/04/2021

DOI: doi.org/10.17533/udea.lyl.n79a07

\begin{abstract}
Resumen: Este trabajo presenta una lectura crítica de las propuestas teóricas más destacadas en torno a la metáfora, con el objetivo de incorporar conceptos teóricos y metodológicos que no han sido considerados para su abordaje. En efecto, se recogen aportes de teorías no referencialistas y no unicistas del sujeto y se adopta la denominación de enunciados metafóricos - EM- un tipo de formulación lingüístico-discursiva de autonomía relativa que exhibe y concentra el funcionamiento del discurso. Se afirma que sus efectos de sentido se producen en el entramado textual en el que aparecen, según las particulares condiciones de producción.
\end{abstract}

Palabras claves: metáfora; enunciados metafóricos; lengua; efectos de sentido; lingüística.

\section{METAPHORS AND METAPHORICAL STATEMENTS: A THEORICAL-METHODOLOGICAL PROPOSAL}

\begin{abstract}
This article presents a critical reading of different perspectives on metaphor. The goal is to introduce theoretical and methodological concepts that have not been accounted for in the study of the concept. In order to incorporate them this article integrates contributions from non-referentialistic and non-unicist theories of the subject and adopts the name of metaphorical utterances, defined and characterized as a type of linguistic-discursive formulation which presents a relative autonomy and displays and concentrates a discursive functioning whose effects of meaning are produced within the textual framework where they appear, according to the particular conditions of production.
\end{abstract}

Key words: metaphor; metaphorical utterances; language; effects of meaning; linguistics.

1. El trabajo forma parte de una investigación mayor que se inscribe en los proyectos UBACYT, radicados en el Instituto de Lingüística de la Universidad de Buenos Aires, y en el Proyecto PICT 2019/2020, subsidiado por la Agencia Nacional de Promoción Científica y Tecnológica de Argentina. En términos más específicos, recoge resultados investigativos que formaron parte de la tesis de doctorado Prácticas discursivas y enunciados metafóricos. Acerca de los efectos de sentido de los enunciados metafóricos en el discurso académico-pedagógico, defendida en febrero de 2019, cuya directora fue la Dra. María Marta García Negroni (UBA- CONICET) y su co-directora la Dra. Mónica Zoppi-Fontana (UNICAMP). 


\section{Introducción}

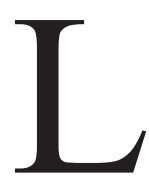

as metáforas han sido fuente de interés en distintas áreas durante siglos: los estudios literarios, la psicología, la filosofía, la teoría de la ciencia, la inteligencia artificial y, por supuesto, la lingüística. En tales contextos investigativos, es fácil comprobar que hay una constante vinculada con las supuestas diferencias entre sentido literal y sentido metafórico. En términos generales, el primero es identificado con el producto de una primera lectura y el segundo con aquel sentido que debe «buscarse», por ejemplo, cuando el primero es considerado erróneo o inadecuado al contexto. También existe la idea en el imaginario social de que el sentido literal es el exacto y verdadero - y, por ello, el propio del discurso científico-, mientras que el metafórico es el figurativo, imaginativo o de dudosa verdad — propio de la literatura-.

Este trabajo considera que lo que se denomina habitualmente como metáfora no es un tropo, un instrumento de la comunicación, o un modo de proyectar representaciones o procesos mentales acerca del mundo. Así, toma distancia del planteamiento dicotómico de sentido literal/sentido metafórico, y abandona el término «metáfora» para adoptar el de enunciados metafóricos — de ahora en más abreviado EM—. Se estudian estos enunciados como un tipo de formulación lingüístico-discursiva de autonomía relativa que exhibe y concentra el funcionamiento del discurso y se afirma que sus efectos de sentido se producen en el entramado textual en el que aparecen, según las particulares condiciones de producción (Pêcheux, 1969).

En trabajos anteriores, el interés se ha puesto en demostrar que tanto el estudio de la metáfora como el del discurso académico involucra otros conceptos que no siempre aparecen explícitos (Hall, 2010). También se ha descrito de qué manera esos conceptos aparecen en diversos análisis de metáforas literarias (Hall, 2013). En esta oportunidad, los centros del estudio son la definición y caracterización de lo que se denomina como EM.

Para la elaboración de esta propuesta, se retoman investigaciones sustentadas en concepciones no «unicistas» del sujeto y no referencialistas ni instrumentalistas de la lengua (García Negroni, 2017, 2019)², dentro de las cuales el análisis del discurso ocupa un lugar central. Esto se refiere al campo disciplinar que inicia en Francia hacia finales de los años sesenta con los aportes de Michel Pêcheux y colaboradores, quienes encuentran tempranamente amplia repercusión y difusión en la Universidade Estadual de Campinas y en los trabajos de Orlandi y de otros investigadores. Desde allí, se expande con fuerza a otras universidades de ese país y, de manera creciente, a las de Latinoamérica ${ }^{3}$.

El enfoque del Análisis del Discurso - abreviado AD — se inscribe en un cuadro epistemológico cuyos fundamentos teóricos se vinculan con la lingüística, el psicoanálisis y el materialismo histórico (Zoppi Fontana, 2013; Siquiera Baldini \& Zoppi Fontana, 2015). Desde sus orígenes, se presenta como un dominio entre disciplinas y no como la aplicación de la lingüística sobre las ciencias sociales o viceversa, esto porque no acumula

2. Estos aportes se inscriben en el marco teórico del Enfoque dialógico de la argumentación y la polifonía (García Negroni, 2016, 2018a, 2018b, 2019; García Negroni \& Libenson, 2020).

3. Los convenios de intercambio entre la Universidade Estadual de Campinas y la Universidad de Buenos Aires, y los seminarios de posgrado impartidos por la Dra. Zoppi Fontana durante la primera década del 2000, permitieron que esta teoría tomara fuerza en la Argentina. 
La metáfora y los enunciados metafóricos: una propuesta teórico-metodológica

conocimientos disciplinares, sino que cuestiona presupuestos (Pêcheux, 1969; Pêcheux \& Fuchs, 1975; Orlandi, 2004). Tal como lo explica Orlandi (2007), el AD discute con la lingüística que deja de lado la historicidad y la exterioridad, cuestiona el materialismo que no incluye lo simbólico y toma en cuenta conceptos del psicoanálisis, pero en relación con la ideología y la historia.

A continuación, se realiza una lectura crítica de distintos enfoques teóricos que se han ocupado hasta hoy de estudiar las llamadas metáforas: se destacan sus aportes y se señalan las diferencias con este estudio — sección 2-. Asimismo, con el objetivo de demostrar la necesidad de incorporar conceptos teóricos, epistemológicos y metodológicos que no han sido considerados aún, se delimita el marco teórico conceptual adoptado (sección 3). A continuación, se ofrecen las características generales de los EM (apartado 4) y, por último, se exponen las conclusiones (sección 5).

\section{Las teorías acerca de la metáfora: una discusión teórica}

Es justo señalar que los primeros trabajos de Aristóteles en torno a las metáforas siguen siendo la lectura inicial de toda investigación que se proponga examinar el tema. Este filósofo estableció efectivamente las ideas fundantes de nombre ajeno y traslación del significado como características del lenguaje metafórico. Según Aristóteles, el lector o el oyente deben realizar un trabajo mental para interpretarlas; por ejemplo, en la metáfora homérica «Aquiles es un león» el poeta transfiere rasgos que pertenecen a los leones —ferocidad, valor, entre otros_ - para que el lector advierta que Aquiles es, en efecto, como un león.

Es también conocido que el estagirita fue quien dio comienzo a dos vertientes: la que considera las metáforas como un recurso de calidad poética — según lo plantea en La Poética (335-323 a.C.) — y la que reflexiona acerca de su poder persuasivo sin limitarse a su uso poético — según lo expone en La Retórica (367-322 a.C.)—.

Como es fácil constatar, durante siglos, distintas teorías posteriores a Aristóteles se han puesto de acuerdo en que la distinción entre lo literal y lo metafórico permite definir y clasificar metáforas. Según esta tradición, a partir de los procedimientos de sustitución y analogía, existen enunciados que, de manera unívoca, exhiben la literalidad, es decir, refieren a las cosas «tal cual son». Luego existen otros enunciados que refieren a las cosas de manera indirecta, es decir, «en sentido figurado». Por ejemplo, un enunciado del tipo «la casa está abierta» no sería una metáfora porque, en tanto refiere de manera directa el estado — está abierta— de un objeto — casa—, debe entenderse como manifestación de un uso literal del lenguaje. Podría pensarse así que «la casa está abierta» carece de ambigüedad.

4. $\quad$ En el capítulo Xxi (1457b) de la Poética (1991), se afirma que la «metáfora es la imposición de un nombre ajeno, en que el género sustituye a la especie, la especie al género, una especie a otra, o hay una analogía. [...] Digo que hay analogía cuando sucede algo semejante a esto: el segundo es al primero como el cuarto al tercero. El poeta dirá, en efecto, "cuarto" en lugar de "segundo" o "segundo" en lugar de "cuarto". Y a veces se agregará aquello que concierne a la palabra sustituida» (p. 32).

5. En la Retórica (1999) se sostiene que «el nombre específico y el corriente y la metáfora es lo único que conviene para el estilo de los discursos en prosa sencilla. Un signo de esto es que sean únicamente ellos los que usa todo el mundo. Porque, en efecto, todos hablan con metáforas, nombres apropiados y nombres específicos, de modo que es evidente que, si uno hace bien sus discursos, el resultado será algo extraño, cabrá disimular (su artificio) y tendrá claridad» (p. 490). 
La metáfora y los enunciados metafóricos: una propuesta teórico-metodológica

De acuerdo con Zoppi Fontana (1991), la ilusión de literalidad supone un lector cuyo gesto de lectura se limita a un acto de reconocimiento como si «as palabras teriam já um sentido (literal, proprio) a ser descoberto» (p. 54). De este modo, la llamada lectura literal es sustentable si esta se basa en el supuesto de que los enunciados tienen un sentido dado y previo a la producción del discurso en el cual aparecen. Contrariamente, de acuerdo con el AD, toda lectura es concebida como trabajo simbólico y, como tal, abre diferentes posibilidades de interpretación que no son previas al acto interpretativo ni dependen de la voluntad de un sujeto: los sentidos no surgen mecánicamente como propiedad privada de quien lee, ni tampoco por generación espontánea, sino que son construidos como parte de un proceso en constante cambio.

Desde esta perspectiva, toda lectura es «regulada» por las condiciones históricas y culturales que hacen que algunos sentidos sean leídos y otros excluidos. No se trata de una relación lineal entre «personas», ni entre las personas y «lo que se dice», sino de complejas relaciones sociales e históricas. En realidad, el sentido literal es aquel que funciona como si fuera el evidente: es un efecto de sentido que genera la ilusión de que las palabras significan «referencialmente» con exactitud lo que dicen. En otros términos, el sentido literal es una construcción producto de una lectura legitimada socialmente como la «verdadera», así los sentidos no habitan los textos, sino que son construidos en los procesos socio-históricos en los que las palabras son producidas e interpretadas.

Es pertinente ahora retomar el ejemplo de «la casa está abierta» y pensar que ese mismo enunciado bien podría pertenecer a un poema. En ese caso, se puede decir que refiere a un objeto o lugar imaginario; «la casa está abierta», entonces, querría decir «algo más de lo que dice». En otras palabras, no se trataría de una descripción «real», sino que formaría parte de una «figuración o fantasía». Como advierte esta vía interpretativa, para distinguir entre lo literal y lo no literal no es suficiente recurrir al valor semántico de las palabras, ni siquiera a la combinatoria entre ellas, sino a elementos de un orden que excede el simple procedimiento de analogía y sustitución de términos.

La idea de que el significado literal surge a partir de la aplicación de reglas que combinan las propiedades de un enunciado es el blanco central de las críticas provenientes de las teorías pragmáticas. En efecto, para Searle (1982), las metáforas constituyen un caso particular de un problema más amplio que consiste en explicar cómo es posible decir una cosa y significar algo más que eso: cómo dar cuenta de la separación que se produce entre el significado del hablante y el significado léxico u oracional. Según este autor, los principios que permiten inferir la interpretación metafórica son exteriores e independientes del sistema léxico de la lengua, esto quiere decir que no depende directamente de la representación semántica del significado lingüístico. El sentido de las metáforas - entendidas como un caso de desvío - se obtiene por inferencia a partir del significado literal y por tal se entiende el conjunto de condiciones de verdad determinado por un contexto concreto (Searle, 1982). Siguiendo con esta propuesta, el significado metafórico es siempre significado proferencial del hablante, significado que se adquiere cuando el enunciado es empleado en circunstancias particulares de uso ${ }^{6}$. Desde esta perspectiva, el sentido metafórico se obtiene por inferencia a partir del sentido literal, una vez se reconoce que este es absurdo ${ }^{7}$,

6. Searle (1982) se ocupa de explicar cómo interpretar metáforas, pero no las define, sino que simplemente afirma que comparten rasgos con otros enunciados tales como ironías, hipérboles, etc.

7. «Quand l'énonciation prise littéralement est défectueuse, rechercher un sens d'énonciation qui diffère du sens de la phrase. » 
y para explicar ese proceso es necesario considerar las intenciones del hablante.

Es importante destacar en esta propuesta teórica del campo de la pragmática, por un lado, su esfuerzo por explicar la interpretación metafórica más allá de la representación semántica del enunciado lingüístico aislado y, por otro lado, la idea de incluir sujetos activos e integrados a una comunidad como variable de análisis. No obstante, además de reafirmar la existencia de un sentido literal y uno metafórico, tanto la idea de hablantes intencionales como la concepción de lenguaje como instrumento al servicio de esos hablantes son factores decisivos para tomar distancia de esta perspectiva (García Negroni, Libenson \& Montero, 2013). Este trabajo no sustenta las ideas de que el hablante transmite significados voluntaria e intencionalmente, y de que el oyente puede determinar sin conflicto cuáles son falsos y cuáles verdaderos. El interés no se centra en distinguir entre el significado lingüístico determinado por el sistema de la lengua — según las reglas de la gramática y la semántica — y el significado comunicativo determinado por el contexto en el que ese sistema es utilizado — según un conjunto de principios que regulan la interacción comunicativa-.

Desde el punto de vista de este artículo y la investigación de la que se desprende, los sentidos no son preexistentes al acto lingüístico-discursivo: el exterior es convocado y al mismo tiempo representado en el discurso. De igual manera, en tanto los efectos de sentido no se producen en relación con el sistema de la lengua, la construcción del sentido metafórico no se explica a partir de la «falsedad» del supuesto sentido literal. Cabe señalar que considerar los sentidos como efectos, implica tomar distancia, por un lado, de la ilusión de transparencia que produce entender los sentidos como «evidencias»; y, por otro lado, implica alejarse de la idea de un sujeto intencional como origen del sentido. Es decir, aquí se estudian los sentidos como formas inacabadas de producción, en permanente proceso de constitución ${ }^{8}$.

Otro aporte que merece ser destacado proviene de la filosofía del lenguaje anglosajona. En declarada oposición a los enfoques sustitutivos y comparativos, el interaccionismo considera que la metáfora no consiste en un desvío que puede ser traducido mediante un reemplazo (Richard, 1936; Black, 1966). Desde esta posición, se afirma que las palabras no tienen sentidos previos al enunciado y que las comparaciones no son válidas porque el parecido entre palabras siempre admite grados y no respuestas definidas. La interpretación de metáforas, entonces, se produciría gracias a un proceso de interacción semántica que pondría en relación dos términos que expresan un nuevo concepto impredecible. Este mecanismo de interacción ocurriría por la evocación de lo que Black (1966) (Searle, 1982, p. 153).

8. Tal como explica Orlandi (2001), el AD reconoce la imposibilidad de un acceso directo a los sentidos. Según la autora, los procesos de producción de sentido contemplan tres momentos indisociables: constitución, formulación y circulación.

9. Richards (1936) toma distancia de la idea acerca de que el significado de las metáforas se vincula con el sentido de palabras aisladas y propone los términos de tenor y vehículo. El primero está vinculado directamente con el significado literal de la palabra y el segundo con lo que se dice. Por ejemplo, en «María es un sol», el tenor es «María» y el vehículo es «sol». Si esto se interpretara «literalmente», implicaría que María es un sol, es decir, un cuerpo celeste; por lo tanto, se caería en un error. Ocurre que en las metáforas existe incompatibilidad entre el tenor y el vehículo, y esta tensión debe ser resuelta por medio de una interpretación metafórica. Las metáforas no surgen, entonces, por medio de una relación de semejanza o comparación, sino por la interacción entre el tenor y el vehículo. 
La metáfora y los enunciados metafóricos: una propuesta teórico-metodológica

denomina «sistemas de rasgos comunes asociados» o «sistemas de tópicos» relativos a un término que aparece en la metáfora ${ }^{10}$.

Estas ideas promovieron el estudio de las metáforas más allá del límite del texto: el interaccionismo propuso un enfoque diferente al comparativo y sustitutivo, habló de «sistemas de cosas» y amplió el marco de estudio de las metáforas al incluir aspectos que exceden el sentido de las palabras. No obstante, al considerar que las metáforas expresan un concepto, gracias al hecho de que ponen en relación dos términos, el mecanismo interpretativo que proponen queda reducido a la relación entre los valores semánticos convencionalizados de esos términos. Por su parte, se señala que esta propuesta contempla las elecciones — intenciones - del hablante; por ejemplo, cuando se refiere a la capacidad que el «lector competente» tiene para elegir los rasgos semánticos de cada término y así encontrar el nuevo sentido que las metáforas crean (Black, 1966, p. 29). Dicho de otro modo, las diferencias entre esta perspectiva y la perteneciente a este artículo residen básicamente en la concepción de sujeto y también en los modos de comprender cómo se construyen sentidos.

Desde el campo de la filosofía analítica ${ }^{11}$, Donald Davidson (1984) no considera que las metáforas tengan un «sentido especial» o nuevo producido a partir de la interacción entre dos ideas; es decir, no está de acuerdo con la afirmación de que la metáfora «says one thing and means another» (p. 44). Es más, según el autor, «no hay un significado metafórico» porque la metáfora no dice nada más allá de su significado literal. Así, el hecho de recurrir a los significados literales de las palabras para explicar una metáfora lleva a pensar que hay oraciones verdaderas o falsas ${ }^{12}$. Tal como afirma Rorty (1996), «mientras que las teorías tradicionales de la verdad preguntaban: “ $¿ A$ qué rasgo del mundo se refiere ‘verdadero’?”, Davidson pregunta: “¿Cómo utiliza ‘verdadero’ el observador exterior del juego de lenguaje?”» (p. 181). De acuerdo con Rorty, resulta central el hecho de que Davidson no identifica la verdad con nada: las oraciones no pueden ser «verificadas» ni por los hablantes ni por el «mundo» exterior. Acertadamente, estima que cualquier «teoría de la verdad» que analice una relación entre fragmentos de lenguaje y fragmentos de no lenguaje está en la senda errónea desde un principio. Por lo tanto, para comprender el uso metafórico no es necesario relacionarlo con «algo» que haya existido antes de la aparición de la metáfora.

El uso metafórico, según Davidson, tiene una función comunicativa — más adelante se refutarán tales observaciones - , que no es la de expresar o transmitir ideas, sino la de hacer notar, indicar, invitar a un auditorio a ver una realidad. Dicho de otro modo, el efecto de las metáforas es el de hacer ver las cosas de otra manera, pero según este autor ver una cosa como otra no es ver que una cosa es otra. En clara oposición al planteo sentido

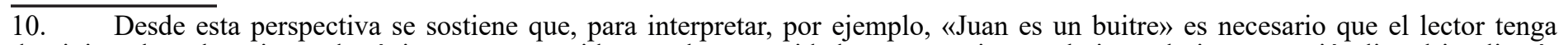
dominio sobre el conjunto de tópicos — compartidos por la comunidad- que remiten a «buitre»: la interpretación literal implicaría considerar erróneamente que Juan es un animal.

11. La filosofía analítica se desarrolla en respuesta a las corrientes idealistas, a partir de las obras de Frege, Russell y Wittgenstein. Entre las preocupaciones de esta corriente se destaca la temática de la «verdad».

12. Para ejemplificar su idea, Davidson (1984) explica que, en una ocasión, cuando el avión de Hemingway había sido destruido en África, el diario Mirror publicó el siguiente titular: «Hemingway Lost in Africa». En este caso, la palabra lost sugería que Hemingway estaba muerto, pero cuando se supo que él estaba vivo, el mismo diario hizo que esa misma palabra tomara sentido literal. Este autor hace notar que el titular del periódico siempre fue el mismo y que lo que había variado había sido el uso de esas palabras. Estas fueron usadas como metáfora cuando se lo consideró falso. Por lo tanto, concluye Davidson, cuando se considera que una oración es falsa, es aceptada como una metáfora. 
La metáfora y los enunciados metafóricos: una propuesta teórico-metodológica

literal/sentido metafórico, esta innovadora propuesta reivindica enfáticamente el significado literal.

Es oportuno, pues, detenerse en esta perspectiva porque constituye un valioso antecedente en los estudios posteriores acerca de las metáforas. En efecto, al sostener que el significado literal de una expresión depende de los usos de los hablantes, en los diferentes procesos comunicativos, este autor propone anticipadamente el enfoque pragmático. Al mismo tiempo, la idea davidsoniana de que las metáforas tendrían la función de hacer ver una realidad también puede considerarse un antecedente del revolucionario enfoque cognitivo.

Al cognitivismo, entretanto, se le debe el haber cuestionado de manera sólida la faz meramente lingüística de la metáfora y su valor como tropo estilístico y retórico (Lakoff \& Johnson, 1998). Esta corriente de pensamiento considera que la metáfora funciona en relación con el sistema cognitivo, que no es individual, sino que está compuesto por representaciones colectivas culturalmente compartidas. En pocas palabras, las metáforas son definidas y analizadas como mecanismos que permiten la conceptualización y reconceptualización del mundo, la organización y reorganización de la realidad. Se trata entonces de una función cognitiva esencial mediante la cual las personas conceptualizan las experiencias.

También es sabido que el término elegido por el cognitivismo es el de proyección metafórica: la metáfora no se explica mediante semejanzas preexistentes, sino por la creación de semejanzas que se producen entre las expresiones lingüísticas metafóricas y el nivel cognitivo experiencial de los sujetos. Vale decir que el cognitivismo no propone una sustitución o una interacción, sino la superposición de dos dominios, uno que se proyecta sobre el otro. En otras palabras, así como las primeras teorías de origen retórico plantean la sustitución entre términos y los planteamientos interaccionales diferencian entre tenor y vehículo (Richard, 1936) o foco y marco (Black, 1966), las perspectivas cognitivas distinguen entre el dominio fuente y el dominio meta.

En una de las etapas siguientes, la autodenominada moderna investigación lingüística basada en el cognitivismo plantea que el estudio del lenguaje no puede separarse de sus funciones cognitiva y comunicativa. En ese contexto, Burdman (2015) habla de postcognitivismo y afirma que, en la actualidad, el cognitivismo abarca múltiples «programas de investigación» que, «con orientaciones y objetivos diversos», adoptan «compromisos teóricos» que presentan «complejas relaciones internas entre sí» (p. 476).

Por cierto, actualmente, en el entrecruzamiento de distintos enfoques, se mantiene la idea de que el pensamiento, primordialmente metafórico, está ligado a la experiencia física y social y se destaca con énfasis la importancia de trabajar con evidencias lingüístico-empíricas. Ejemplo de esto es el trabajo de Vereza (2010), en el que se promueve la articulación entre varias dimensiones de las metáforas — sociocognitiva, lingüística y discursiva- . La idea de que las metáforas revelan dinámicas conceptuales habituales también es central en la investigación que se preocupa por «añadir una nueva perspectiva al análisis lingüístico de las emociones» y, para esto, toma como objeto de estudio un corpus compuesto por cuentas corporativas de Twitter (Fernández-Vallejo, 2018).

En esta línea y en el marco del estudio del uso de las metáforas en contextos discursivos y culturales, Monserrat Planelles Iváñez (2014) da por supuestas la relación entre las metáforas y el conocimiento del mundo y la cristalización de valores en la conciencia de los hablantes de una misma identidad cultural. Así, analiza las 
La metáfora y los enunciados metafóricos: una propuesta teórico-metodológica

metáforas como fuentes productivas de creación léxica en distintos idiomas. En una línea similar de pensamiento, Guiomar Elena Ciapuscio (2013), afirma que las metáforas desempeñan un papel crucial en la creación de terminologías, debido a su potencial epistemológico para estructurar y concebir objetos y fenómenos sobre la base de analogías con otros objetos y dominios cotidianos. Esta autora complementa la teoría conceptual de la metáfora con el estudio de corpus, para lo cual tiene en cuenta la influencia de factores como el género, el contexto, el contenido y la cultura en la elección y empleo de metáforas. Ciapuscio (2013) entiende, entonces, que la metáfora es uno de los procedimientos morfológicos y semánticos de los que disponen las lenguas naturales para resolver «la necesidad expansiva que tienen las distintas ramas del conocimiento de crear terminologías» (p. 173).

Eduardo de Bustos (2013), también interesado por el poder innovador de las metáforas, retoma el principio de invariancia cognitiva de Lakoff (1990) y advierte que la metáfora y el razonamiento analógico — que esta trae aparejado_ «satisfacen una necesidad cognitiva» del «innovador conceptual» (p. 16). Este, guiado por sus objetivos y su contexto situacional, «encuentra o descubre una metáfora apropiada y un conjunto de inferencias relevantes» (p. 16). Según Bustos, mientras la creatividad se define en relación con el conocimiento de un paradigma o comunidad epistémica, la innovación exige «el reconocimiento y aceptación de una comunidad epistémica y del conjunto de la sociedad.» (p. 13). En muchas ocasiones, para este autor, las soluciones innovativas crean el entorno teórico y dan sentido a sus propuestas.

Por su parte, Nelly Rueda (2019) analiza la dimensión cognitivo-argumentativa de las metáforas dentro del discurso polémico de entornos virtuales. Para esto, también recupera los trabajos de Lakoff y Johnson (1998) y, en lo que denomina un «cruce disciplinar», retoma aportes de Wodak (2001) inscritos en la perspectiva delAD. Para la autora (2019), las metáforas no solo son un procedimiento cognitivo, sino también un «potente recurso ideológico», en cuanto tienen el poder de «aprehender la realidad» y crear «realidades en tanto nuestro sistema conceptual establece lo que es real» (p. 187) ${ }^{13}$. Según Rueda, las funcionalidades argumentativas e ideológicas de las metáforas están vinculadas entre sí de manera indisoluble porque construyen discursivamente la realidad a la que se refieren y operan como apoyos argumentativos en el proceso de razonamiento, apelando al pathos del oyente y reproduciendo significados culturales e ideológicos.

Como puede constatarse, la revolución conceptual iniciada por Lakoff y Johnson (1998) sigue vigente. En otras palabras, se puede afirmar que existe un alto grado de consenso en considerar que «la esencia de la metáfora es entender y experimentar un tipo de cosa en términos de otra» (Lakoff \& Johnson, 1998, p. 41). A partir de esta idea, numerosos trabajos indagan sobre «los recursos que ofrece el lenguaje para representar, expresar y construir realidades.» (Sánchez Rivera, 2020, p. 107).

En este punto, es oportuno recuperar un trabajo de Jonathan Culler (1988) cuando afirma que las oposiciones binarias constituyen conjuntos de categorías con pretensiones de descripción que pueden parecer simétricas, pero

13. Según Nelly Rueda (2019), ejemplos de esto sería denominar a las tendencias populistas como un «cáncer» o al aborto como un «asesinato». 
La metáfora y los enunciados metafóricos: una propuesta teórico-metodológica

que funcionan jerárquicamente ${ }^{14}$. En este sentido, cabe preguntarse si la relación entre los dominios meta y fuente que el cognitivismo plantea no es, en realidad, de orden jerárquico ${ }^{15}$. De cualquier modo, la correspondencia entre mente y palabras — fuente de todas las propuestas vigentes - debe ser repensada. Por ejemplo - y en cuanto a la correlación entre la formación de palabras y de conceptos - desde la filosofía del lenguaje, Carlos Emilio Gende (2016) demuestra que el sistema de constitución conceptual no es análogo a la conformación del sistema lingüístico. Al parecer, la dificultad «en establecer una correlación entre formación de palabras y conceptos» se debe a que «se trata de dos sistemas heterogéneos con reglas de constitución distintas» (Gende, 2016, p. 107) ${ }^{16}$.

De acuerdo con lo expuesto hasta este punto, puede observarse que las perspectivas resumidas constituyen valiosos aportes que permiten repensar temas y problemas ${ }^{17}$. En términos generales, se observa que los planteamientos vigentes se inscriben en una larga tradición de estudios que se apoyan en la idea de que la lengua es un instrumento de comunicación destinado a transmitir ideas, producir efectos o «hablar» de los objetos del mundo. En consonancia con Schulz (2000; 2002; 2004), se puede afirmar que, en la noción de proyección de un dominio a otro, pervive una visión referencialista de la lengua, ya que solo dentro de esta visión se puede afirmar que un término remite a «otra cosa» ${ }^{18}$. Dicho de otro modo, según una concepción referencialista e instrumentalista, la lengua ofrecería opciones para que los sujetos elijan las palabras o enunciados que remiten a «cosas» de acuerdo con sus propósitos comunicativos y expresen lo que ellos quieren decir: las metáforas serían uno de esos enunciados.

Respecto a la noción de sujeto, se ha constatado que este concepto no aparece problematizado en las propuestas iniciales. Es así como, en el enfoque pragmático, es considerado como un sujeto intencional y, en los estudios de corte cognitivistas, el sujeto es tratado con el estatuto de entidad observable, cuyo modo de funcionamiento mental y lingüístico puede ser descrito en términos de interacción con el medio y con la supuesta realidad.

Contrario a lo anterior, este trabajo considera que la lengua no es soporte de pensamiento ni tampoco instrumento de comunicación exterior al sujeto, sino que es parte constitutiva de él. Para el AD, la lengua no

14. Culler (1988) explica que de un supuesto orden secuencial —el sentido literal es primero y el metafórico es la manifestación o separación del anterior- se pasa a un orden jerárquico sin más: lo literal es más «verdadero» y «genuino» — positivo—, mientras que lometafórico, que viene después, se asocia con «lo engañoso» — negativo-.

15. Esta idea de secuencialidad se evidencia, por ejemplo, cuando se afirma que «una vez que podemos identificar nuestra experiencia como identidades o sustancias, podemos referirnos a ellas, categorizarlas, agruparlas, cuantificarlas y, por este medio, razonar acerca de ellas» (Lakoff \&Johnson, 1998, p. 25).

16. Gende (2016) revisa núcleos decisivos del cognitivismo para demostrar sus límites. Afirma que «la formación de la expresión puede obedecer a la configuración por el significante o por el contenido del significado tal como ocurre con "me hizo la pera" y "me viene de perillas"》 (p. 107). Explica que «me hizo la pera» obedece a una contracción fónica de «me hizo esperar», mientras «me viene de perillas» solo se explica por el contenido. «Me viene de perillas» significa «me viene a la mano» porque el término «perilla» remite a la forma que tiene la agarradera de la montura de los caballos que se usa como un elemento cómodo y seguro para «agarrarse».

17. Es pertinente señalar que no solo las teorías expuestas han sido resumidas, sino que — por razones de espacio- también se ha establecido una selección de propuestas, dejando de lado otras. De las dos tradiciones que establece Mukhortikova (2018) queda pendiente la revisión y la discusión con la visión formalista.

18. En trabajos anteriores (Hall, 2010,2013), se han expuesto las tres hipótesis que, según Schulz, son comunes a las definiciones de metáfora y que también suelen aparecer en diccionarios y enciclopedias. Estas son las del « dédoublement des emplois »; « changement de sens »; « l'hypothèse du transfert » y a estas se les suma la de « la ressemblance ». 
La metáfora y los enunciados metafóricos: una propuesta teórico-metodológica

es un objeto que el sujeto controle y domine voluntariamente: la relación entre el lenguaje y «la realidad» no es directa porque las palabras no refieren a objetos del mundo real, sino que «refieren» simbólicamente. La lengua es considerada la condición de posibilidad del discurso: es un lugar material en el que se realizan los efectos de sentido, que son históricos e ideológicos.

Desde este contexto teórico, este artículo sostiene que quien habla no es dueño absoluto de su decir. Por lo tanto, no se trata de indagar sobre lo que «el autor quiso decir», sino sobre cómo sus palabras, puestas en discurso, materializan efectos de sentido que no son intencionales ni voluntarios. Analizado a la luz de una determinada posición de sujeto (Courtine, 1981), el sujeto es pensado como un lugar de significación históricamente construido. Además, la idea de posición de sujeto no corresponde a un espacio físico, ni a un lugar objetivo en la estructura social, sino que se trata de un lugar social representado en el discurso.

En síntesis, el planteamiento de la relación entre la metáfora, tal como aparece — objeto lingüístico presentey el concepto o idea — objeto mental ausente - constituye un método de análisis insuficiente. Para estudiar los EM se toman en consideración conceptos teóricos, epistemológicos y metodológicos —i.e. funcionamiento discursivo, proyecciones imaginarias, efectos de sentido, y condiciones de producción- que permiten dar una explicación no referencialista y discursiva de los EM y que, de acuerdo con el rastreo bibliográfico, no han sido considerados. En el próximo apartado se trabajan tales conceptos.

\section{Los enunciados metafóricos: delimitación del marco teórico conceptual}

Para avanzar con esta propuesta, es pertinente retomar una idea central del AD: este trabajo no busca conocer «qué dicen los textos»o «qué quiso decir el autor». Al contrario, este trabajo indaga sobre los modos de significación y procura comprender el proceso del funcionamiento discursivo ${ }^{19}$. Esto implica un alejamiento de la perspectiva hermenéutica que entiende la lectura como el acto de extracción de un sentido del texto (Orlandi, 2003).

De acuerdo con Orlandi (2003), el funcionamiento del discurso o funcionamiento discursivo es un proceso mediante el cual se configuran y materializan recíprocamente objetos y sujetos, es decir, la conformación de los objetos del discurso y de los procesos imaginarios de subjetivación hace al funcionamiento del discurso. De este modo, el sujeto hablante deja de ser pensado como un único sujeto real para ser considerado discursivamente como parte de la materialización de un proceso de significación determinado. Por su parte, el objeto es analizado en su constitución variable y no como una homogeneidad referencial. Estos procesos que dan cuenta del funcionamiento del discurso, en permanente construcción, constituyen el punto de partida, la descripción y el análisis de los efectos de sentido de los EM.

En términos generales, este trabajo considera que los EM no conforman unidades factibles de ser analizadas en

19. Centrarse en el estudio del funcionamiento discursivo implica tomar distancia de perspectivas que presuponen un hablante que «se apropia» del discurso: el sujeto no se apropia de la lengua en un movimiento individual (Orlandi, 2003, p. 61), «há uma forma social de apropriação da linguagem em que está refletido o modo como ele o fez, ou seja, sua ilusão de sujeito, sua interpelação feita pela ideología.» (p. 27). 
La metáfora y los enunciados metafóricos: una propuesta teórico-metodológica

forma independiente del hilo del discurso, sino que constituyen formulaciones lingüístico-discursivas que irrumpen en el hilo del discurso con distintos grados de visibilidad. Y, en tanto aparecen como un cuerpo medianamente extraño, de acuerdo con Authier-Revuz (1982), se ubican en lo que la autora denomina heterogeneidad mostrada, definida como una especie de negociación del sujeto hablante con la heterogeneidad que lo constituye.

Es necesario recordar que Authier-Revuz (1984) reformula los planteamientos de Bajtín sobre el dialogismo y retoma la relación del sujeto con el lenguaje propuesta por Freud y reelaborada por Lacan, para así introducir el concepto de heterogeneidad enunciativa y defender la idea de que el sujeto vive con la ilusión necesaria de autonomía de su conciencia y de su discurso; aunque, en realidad, el sujeto está irreductiblemente dividido por el inconsciente. Y, aun cuando no haya en su discurso huella visible, la presencia del «Otro» ${ }^{20}$ emerge porque es constitutiva del sujeto: la idea de heterogeneidad de la palabra se articula entonces con la de descentramiento del sujeto ${ }^{21}$. Los procedimientos que vulneran la ilusa unidad monológica del discurso se corresponden con dos tipos de heterogeneidades: la constitutiva y la mostrada. La heterogeneidad constitutiva se sustenta en la idea de que en todo discurso hay «Otro» que lo determina más allá de la voluntad del sujeto. La heterogeneidad mostrada, por su parte, se basa en la idea de que el desdoblamiento del sujeto y la presencia de otros aparecen representados en los enunciados (Authier-Revuz, 1982; 1984; 1995). Ahora bien, la heterogeneidad mostrada se materializa en el discurso a través de un conjunto de formas marcadas y no marcadas. Las formas no marcadas de la heterogeneidad mostrada representan una forma más «arriesgada» de negociación, ya que juegan con la dilución o disolución del otro en uno: la presencia del otro aparece solapada., Algunos ejemplos de estas formas, sin ruptura sintáctica y muy cerca de la heterogeneidad constitutiva según Authier-Revuz, son el discurso, la ironía, las metáforas y los juegos de palabras.

Asimismo, Authier-Revuz afirma que, mediante las formas marcadas de la heterogeneidad mostrada, el sujeto se presenta ilusoriamente como si controlara su discurso, esto es, como dueño exclusivo de su producción: al tiempo que delimita y circunscribe en su discurso el discurso del otro, el resto queda como si fuera absolutamente propio. La heterogeneidad mostrada marcada — que se manifiesta en puntos localizables como irrupciones en el hilo del discurso - es una suerte de «síntoma» de la heterogeneidad constitutiva. Por una especie de «compromiso precario», formas tales como el discurso directo, el discurso indirecto o la presencia de comillas dan lugar a que lo heterogéneo se manifieste como modos particulares de decir. Se trata de diversas formas mediante las cuales el discurso se desdobla, lo cual indica que el sujeto percibe una no coincidencia. Estas no coincidencias no se derivan de la intencionalidad de los sujetos, sino de posiciones enunciativas particulares que se definen

20. De origen lacaniano, el concepto de el Otro se diferencia del otro. Mientras el primero reporta al inconsciente, el segundo refiere a la exterioridad constitutiva del sujeto - esto es, otras voces, otros sujetos-. El petit autre es el otro que no es realmente otro, sino una proyección del yo - que está inscrito en el orden imaginario-. El gran Otro designa la otredad que trasciende la otredad ilusoria de lo imaginario y se inscribe en el orden simbólico. Lacan equipara esta alteridad con el lenguaje y la Ley.

21. Según Authier-Revuz, « pour un sujet divisé, “clivé”, (et non pas “dédoublé”) il n’y a pas de centre, d'où émanerait en particulier le sens et la parole, hors de l'illusion et du fantasme; mais que maintenir cette illusion d'un centre est la fonction, nécessaire et normale du moi, pour le sujet. Pour un sujet qui, fondamentalement, est un "effet de langage", il n'existe pas, hors de l'illusion, -là encore nécessaire et normale- de position d'extériorité par rapport au langage, d'où le sujet parlant pourrait prendre de la distance. \) (1982a, p. 141). 
La metáfora y los enunciados metafóricos: una propuesta teórico-metodológica

discursivamente y que implican un retorno reflexivo del decir sobre sí mismo, según cuatro modalidades: a) nocoincidencia interlocutiva entre los dos co-enunciadores, lo cual materializa un debate con la alteridad e intenta preservar una frontera entre el discurso propio y el del otro; b) no-coincidencia del discurso consigo mismo, lo que manifiesta la presencia de otros discursos en el propio. Esta relación entre un interior y un exterior, ambos discursivos, pretende asegurar la unidad y la identidad del discurso; c) no-coincidencia entre las palabras y las cosas, que señala las distancias entre las palabras y su correspondencia exacta con las representaciones «reales» que esas palabras refieren; en otros términos, indica que las palabras empleadas no se corresponden exactamente con la realidad referida, d) no-coincidencia de las palabras consigo mismas, que remite al juego entre la polisemia y la homonimia e indica que el sentido de las palabras está afectado por otros sentidos y que alguno de ellos es equívoco.

En esta línea de pensamiento, entonces, lo que se denomina EM podría ubicarse dentro de las formas no marcadas de heterogeneidad mostrada tal como Authier-Revuz lo hace con las metáforas. No obstante, en tanto estos enunciados presentan cierto efecto de unidad que los hace identificables, pueden ubicarse como las formas más marcadas de la heterogeneidad mostrada no marcada, aunque en ocasiones pueda tratarse de formas mostradas marcadas.

\section{Las características generales de los EM}

A partir de las ideas expuestas en el apartado anterior, es posible afirmar que los EM constituyen una manera de inscribir al otro en el hilo del discurso: materializan la heterogeneidad por medio de las cuales el sujeto emerge. La relación entre las palabras — que le imprime estabilidad estructural a los EM- produce, a su vez, efectos alusivos de repetición (García Negroni, 2019). Dado el aspecto alusivo de los EM, estos funcionan a modo de recuerdos de discursos previos que retoman, transforman, enmascaran o exhiben aspectos de esos mismos discursos, no siempre de modo explícito (García Negroni, 2019). Este efecto unido al carácter metaenunciativo y reflexivo del propio sujeto enunciador facilitan igualmente la identificación y el reconocimiento de su presencia en el discurso.

En este sentido, los EM funcionan como efecto de preconstruido. Paul Henry (1992) propone este término para dar cuenta de una construcción anterior e independiente de lo que es «construido» en el propio discurso. Según Courtine (1981), se trata del efecto discursivo ligado al encadenamiento sintáctico: «un elemento del interdiscurso [...] se encadena en el intradiscurso como si este elemento ya se encontrara allí de antemano» (p. 40). Por su parte, Pêcheux (1975) define el mismo como un elemento que irrumpe en un enunciado, como aquello que fue pensado antes o en otro lugar, produciendo un sentido de evidencia. En el mismo orden, Marandin (2010) postula que el concepto designa una situación en la que el modo de organización del objeto es indistinguible de su modo de interpretación y, en tanto se relaciona con lo «ya dicho», restringe la interpretación y sustenta la posibilidad del decir. Como afirma Orlandi (2007), toda vez que se habla, se produce «uma mexida na rede de 
filação dos sentidos, no en tanto, falamos com palavras já ditas.» (p. 36).

Así, se entiende que los EM revelan la alteridad implícita que conlleva el proceso de anticipación. De acuerdo con Pêcheux (1969), «todo proceso discursivo supone, por parte del emisor, una anticipación de las representaciones del receptor, sobre la cual se funda la estrategia del discurso» (p. 50). Esto implica afirmar que las proyecciones

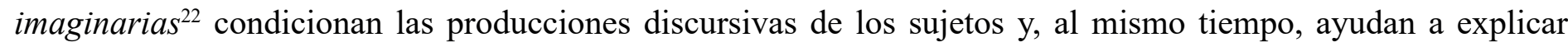
los modos de construcción de sentido. Este proceso de producción e interpretación en el que las condiciones de producción están presentes es propio de toda producción discursiva; pero los EM lo hacen ostensible. De este modo, estudiar los EM como formulaciones insertas en una dinámica discursiva implica pensarlos como parte de una actividad estructurante de un discurso determinado, para un interlocutor particular, según condiciones de producción específicas. Los efectos de sentido de los EM — al igual que la identidad de los sujetos- son producidos a partir de las posiciones de sujeto que no son individuales ni universales, sino determinadas por una coyuntura histórica dada en el marco del desarrollo de las prácticas discursivas.

Los efectos de sentido de los EM se producen en tanto parte de un proceso discursivo más amplio y continuo, y en relación con determinadas condiciones de producción que «representam o mecanismo de situar os protagonistas e o objeto do discurso» (Orlandi, 2003, p. 117). Se trata de pensar la «exterioridad» no como un elemento ajeno, sino como constitutiva del discurso. Los sujetos habitan el propio discurso como ilusión subjetiva, como proyección imaginaria de los lugares sociales que los interlocutores ocupan en el discurso (Pêcheux, 1975), y las variaciones interlocutivas son construidas en el entramado de los modos de decir que dan forma a los discursos.

De acuerdo con lo expuesto hasta aquí, se ofrecen a continuación las características generales de los EM:

- Presentan con distintos grados un efecto de unidad que les otorga estabilidad estructural y visibilidad discursiva. Este efecto también se logra porque funcionan alusivamente como preconstruidos en relación con el interdiscurso.

- No se trata de objetos que pueden interpretarse como unidades autónomas, sino que deben ser leídas en el hilo del discurso en el que aparecen, de acuerdo con la representación imaginaria de los sujetos, y según las condiciones de producción.

—En relación con el fenómeno de anticipación, constituyen casos de heterogeneidad mostrada e irrumpen en el hilo del discurso como manifestación más o menos marcada de la presencia del otro. Como tal, forman parte de los procesos de subjetivación.

- Su particularidad consiste en que sus efectos de sentido concentran y hacen ostensible el funcionamiento de ese discurso. En este sentido, son espacios privilegiados para analizar la construcción de los sujetos y objetos discursivos.

Ahora bien, estas características generales adquieren sus particularidades según el discurso en el que los EM aparecen. Por ejemplo, mientras los EM presentes en poemas concentran y exhiben el funcionamiento del discurso

\footnotetext{
22. Las formaciones imaginarias, en tanto mecanismos de funcionamiento discursivo, no hablan respecto de los sujetos físicos o los lugares empíricos, sino de las imágenes que resultan de las proyecciones que los sujetos construyen de sí mismos, de su interlocutor y del objeto de su discurso (Pêcheux, 1969).
} 
La metáfora y los enunciados metafóricos: una propuesta teórico-metodológica

poético, los presentes en manuales universitarios concentran y exhiben el funcionamiento del discurso académico pedagógico. En ambos casos, el análisis que aquí se propone constituye una alternativa interpretativa que toma en consideración tanto el hilo del discurso en el que estos enunciados aparecen - funcionamiento correferencial o endofórico - , como sus vínculos con las condiciones de producción — funcionamiento exofórico-, en relación con discursos previos o con el interdiscurso. Será objeto de otros trabajos exponer en detalle la descripción y el análisis de EM presentes en manuales universitarios y, así, demostrar que estos enunciados constituyen espacios privilegiados para analizar la construcción de los sujetos y de los objetos discursivos; esto es, el funcionamiento del discurso.

\section{Conclusión}

En este trabajo, se han destacado aportes y señalado diferencias vinculadas con líneas teóricas que se han ocupado de estudiar las metáforas, denominadas como EM. Como ya se ha dicho, se considera que no se trata de una figura del lenguaje, de un instrumento de la comunicación, o de un modo de proyectar representaciones o procesos mentales acerca del mundo. En tanto los EM no son un hecho de la lengua sino del discurso, los efectos de sentido que estos enunciados materializan no se construyen como si fueran unidades lingüísticas autónomas, ni en relación con otros términos —objetos - a los que supuestamente podrían remitir. Tampoco se construyen en relación con la mente de los sujetos, sino como parte de una textualización que se produce en el marco de una práctica social. Tal como los «puntos de basta» ${ }^{23}$, al modo de los hilos que se tensan y producen depresiones en la superficie, su presencia se hace visible y sus efectos de sentido se producen en el hilo del discurso en el que aparecen por el entrecruzamiento con otros segmentos textuales. Estos efectos también se logran porque funcionan alusivamente como preconstruidos en relación con el interdiscurso (García Negroni, 2019; Henry, 1992; Pêcheux, 1975).

A partir de las características generales desarrolladas, se concluye que para analizar los efectos de sentido de los EM es necesario tomar en consideración la relación entre palabras y enunciados presentes en el texto y entre estos y otros evocados alusivamente que, en tanto memoria discursiva, remiten a representaciones históricas y sociales. Se trata de dar cuenta del funcionamiento del discurso que los EM condensan y hacen ostensible. Y esto es así en tanto el lenguaje no se concibe como soporte de pensamiento o instrumento de comunicación exterior al sujeto: al contrario, el sujeto que produce e interpreta lenguaje se constituye en él. Se trata de un sujeto que, al estar atravesado por el lenguaje, el inconsciente y la ideología, no necesariamente controla su decir.

De las teorías retomadas, se han recortado los aspectos teórico-metodológicos estimados pertinentes para cumplir con los objetivos propuestos. En esta tarea de selección y adaptación se han producido desplazamientos

23. Se retoma la idea de punto de basta lacaniano que remite a la operación de «puntada» a través de la cual «el significante detiene el deslizamiento de la significación que, de otro modo, sería indefinido» (Lacan, 1989, p. 785). El autor da el ejemplo de punto almohadillado o capitoné que se hace por entrecruzamiento de hilos y que por tensión produce depresiones en la superficie para explicar que el efecto de significado se produce siempre por retroacción de las secuencias significantes. Según Lacan, la puntuación que permite otorgar sentido a una frase es análoga a la tensión de los hilos. 
de sentidos. Es del interés de esta investigación que las reformulaciones teóricas y metodológicas que se han producido - en el recorte y adaptación del marco teórico — sean consideradas como espacios alternativos de discusión.

En la misma línea, el objetivo central de este trabajo ha sido confirmar la necesidad de incorporar categorías conceptuales y epistemológicas que permitan abordar la descripción y el análisis de los EM así como la complejidad de los efectos de sentidos que estos enunciados producen y que la interpretación tradicional suele pasar por alto. Finalmente, es parte del mismo objetivo que esta propuesta sea tenida en cuenta para originar nuevas preguntas y discusiones. 


\section{Referencias bibliográficas}

1. Aristóteles (1991). Poética. Caracas: Monte Ávila.

2. Aristóteles (1999). Retórica. Madrid: Gredos.

3. Authier-Revuz, J. (1982). Hétérogénéité montrée et hétérogénéité constitutive : éléments pour une approche de l'autre dans le discours. DRLAV, 26, 91-151.

4. Authier-Revuz, J. (1984). Hétérogénéité(s) énonciative(s). Langages, 73, 98-111.

5. Authier-Revuz, J. (1995). Ces mots qui ne vont pas de soi. Boucles réflexives et non-coincidences du dire. Paris : Larousse.

6. Black, M. (1966). Modelos y Metáforas. Madrid: Tecnos.

7. Burdman, F. G. (2015). El post-cognitivismo en cuestión: extensión, corporización y enactivismo. Principia, 19(3), 475-495. https://periodicos.ufsc.br/index.php/principia/article/view/1808-1711.2015v19n3p475

8. Ciapuscio, G. (2013). Las metáforas en las cartas de lectores de revistas científicas. RÉTOR, 3(2), 168-186.

9. Courtine, J. J. (1981). Analyse du discours politique [Le discours communiste adressé aux chrétiens]. Langages, $62,1-128$.

10. Culler, J. (1988). La crítica postestructuralista (Trad. D. Navarro). Criterios, 21-24, 33-43. http://www. criterios.es/pdf/cullercritica.pdf

11. Davidson, D. (1984). What Metaphors Mean. En D. Davidson (Ed.), Inquiries into Truth and Interpretation (pp. 245-264). Oxford: Clarendon Press.

12. De Bustos, E. (2013). Argumentando una innovación conceptual: metáfora y argumentación analógica. Revista Iberoamericana de Argumentación, 7, 1-17. https://revistas.uam.es/index.php/ria/article/view/8182 229

13. Fernandez-Vallejo, A. M. (2018). Metáforas y emociones en el Twitter corporativo: una aproximación discursivo-lingüística a los microblogs de Acciona e Iberdrola. Círculo de Lingüística Aplicada a la Comunicación, 73, 125-144. https://revistas.ucm.es/index.php/CLAC/article/view/59062

14. García Negroni, M. M. (2016). Polifonía, evidencialidad citativa y tiempos verbales. Acerca de los usos citativos del futuro morfológico y del futuro perifrástico. En R. González Ruiz, D. Izquierdo Alegría \& Ó. Loureda Lamas (Eds.), La evidencialidad en español: teoría y descripción (pp. 279-302). Madrid: Iberoamericana.

15. García Negroni, M. M. (2017). El enfoque dialógico de la argumentación y la polifonía. Acera de los puntos de vista alusivos. 25th. International Conference. IPrA; Belfast.

16. García Negroni, M. M. (2018a). Argumentación y puntos de vista evidenciales citativos: acerca de la negación metadiscursiva en el discurso político. Oralia, 21(2), 223-242.

17. García Negroni, M. M. (2018b). Argumentación y puntos de vista evidenciales: acerca del condicional citativo en el discurso periodístico y en el discurso científico. Boletín de Lingüística, XXX (49-50), 86-109.

18. García Negroni, M. M. (2019). El enfoque dialógico de la argumentación y la polifonía, puntos de vista evidenciales y puntos de vista alusivos. Rilce. Revista de Filología Hispánica, 35(2), 521-549. 
La metáfora y los enunciados metafóricos: una propuesta teórico-metodológica

19. García Negroni, M. M. (2020). La polifonía en el hablar. Manual de lingüística del texto. Berlín: Gruyter. 20. García Negroni, M. M. y Libenson, M. (2020). La evidencialidad desde el Enfoque dialógico de la argumentación y de la polifonía. Un estudio contrastivo de los empleos inferencial y citativo del marcador evidencial así que. En Ó. Loureda Lamas, M. Rudka y G. Parodi (Eds.), Marcadores del discurso y lingüística contrastiva en las lenguas románicas (pp. 41-62). Madrid: Iberoamericana.

21. García Negroni, M. M., Libenson, M. y Montero, A. S. (2013). De la intención del sujeto hablante a la representación polifónica de la enunciación. Acerca de los límites de la noción de intención en la descripción del sentido. Revista de Investigación Lingüística, 16, 237-262. http://revistas.um.es/ril/article/view/208751

22. Gende, C. (2016). Metáfora y concepto: ¿Ricoeur crítico de Lakoff y Johnson? Logos: Revista De Lingüística, Filosofía Y Literatura, 26(1), 102-110. http://dx.doi.org/10.15443/RL2607

23. Hall, B. (2010). La construcción de sentido: el caso de los enunciados metafóricos y el discurso académico. Tópicos del Seminario «Semántica einterpretación», 23, 191-220.http://www.scielo.org.mx/scielo.php?script=sci_ arttext\&pid=S1665-12002010000100006

24. Hall, B. (2013). Enunciados metafóricos y presupuestos teóricos: un caso de «metáfora literaria». Signo \& Seña, 23, 143-164. http://revistas.filo.uba.ar/index.php/sys/article/view/55

25. Henry, P. (1992). A ferramenta imperfeita: língua, sujeito e discurso. Campinas: Editora da Unicamp.

26. Lakoff, G. (1990). The Invariance Hypothesis: Is Abstract Reason Based In Image Schemas? Cognitive Linguistics, 1, 39-74.

27. Lakoff, G. y Johnson, M. (1998). Metáforas de la vida cotidiana. Madrid: Cátedra.

28. Marandin. J. M. (2010). Sintaxe, discurso: do ponto de vista da análise do discurso. En E. Orlandi (Org.), Gestos de leitura: da história no discurso (pp. 117-141). Campinas: Editora da Unicamp.

29. Mukhortikova, T. (2018). La metáfora en el siglo xx: dos maneras de interpretar el concepto. Lingüistica y Literatura, 74(39), 130-143. https://revistas.udea.edu.co/index.php/lyl/article/view/334476

30. Orlandi, E. (2003). A Linguagem e seu funcionamento. As formas do discurso. Campinas: Pontes.

31. Orlandi, E. (2004). Interpretação: autoria, leitura e efeitos do trabalho simbólico. Petrópolis: Vozes.

32. Orlandi, E. (2007). Análise de discurso: Princípios \& procedimentos. Campinas: Pontes.

33. Pêcheux, M. (1969). Hacia el análisis automático del discurso. Madrid: Gredos.

34. Pêcheux, M. (1975). Les vérités de la Palice. Paris : Maspero.

35. Planelles Iváñez, M. (2014). La metáfora como fuente de creación léxica en el lenguaje publicitario del turismo en francés y en español. Çédille, Revista de Estudios Franceses, 10, 305-318.

36. Richards, I. A. (1936). The Philosophy of Rhetoric. Oxford: Oxford University Press.

37. Rorty, R. (1996). Objetividad, relativismo y verdad. Escritos filosóficos. Barcelona: Paidós.

38. Rueda, N. (2019). Las metáforas como recurso argumentativo en el discurso polémico. En C. Borzi y E. Menéndez (Comps.), Lingüística Cognitiva: Discurso - Gramática - Enseñanza (pp. 185-198). San Luis: Nueva Editorial Universitaria UNSL. 
39. Sánchez Rivera, S. L. (2020). ¿De qué hablamos cuando hablamos de amor? Análisis de las metáforas del amor en canciones de por rock en español. Lingüística y Literatura, 41(77), 106-124. https://doi.org/10.17533/ udea.lyl.n77a05

40. Schulz, P. (2000-2003). Saussure et le sens figuré. En C. Cortès (Ed.), La métaphore. Du discours général aux discours spécialisés. Cahier du C.I.E.L. (pp. 97-108). http://www.eila.univ-paris-diderot.fr/_media/recherche/ clillac/ciel/cahiers/00-03/saussure-schultz.pdf

41. Schulz, P. (2002). Le caractére relatif de la métaphore. Langue française, 134(1), 21-37. 10.3406/1fr.2002.6451 42. Schulz, P. (2004). Description critique du concept traditionnel de « métaphore ». Berne : Peter Lang.

43. Searle, J. R. (1982). Metaphor. En A. Ortony. (Ed.), Metaphor and Thought. Cambridge: Cambridge University Press.

44. Siqueira Baldini, L. J. y Zoppi Fontana, M. (2015). A Análise Do Discurso No Brasil. (2014). Décalages, 1(4), 1-20. http://scholar.oxy.edu/decalages/vol1/iss $4 / 22$

45. Vereza S. (2010). O Lócus da metáfora: Linguagem, pensamento e discurso. Cadernos de Letras da UFFDossiê: Letras e Cognição, 41, 199-212.

46. Wodak, R. (2001). El enfoque histórico del discurso. En R. Wodak \& M. Meyer (Comps.), Métodos de análisis crítico del discurso (pp. 101-142). Barcelona: Gedisa.

47. Zoppi Fontana, M. (1991). Os sentidos marginais. Leitura: Teoria e Prática, 10(18), 48-58.

48. Zoppi Fontana, M. (2013). El análisis del discurso en Brasil: teoría y práctica. Signo y Seña, 24, 3-9. 